\title{
Educação do século XXI: a resiliência dos professores e as re(i)novações no ensino primário em Portugal
}

\section{1st century education: the resilience of teachers and the re(i)novations in primary education in Portugal}

\author{
Ana Nobre \\ Doutora - Professor Auxiliar \\ Universidade Aberta - Uab \\ Lisboa - Portugal \\ Ana.Nobre@uab.pt \\ Ema Cruz \\ Doutoranda \\ Universidade Aberta - Uab \\ Lisboa - Portugal \\ emacruzdle1002382@gmail.com
}

Resumo: Na Educação como em muitas outras vertentes, precisamos que o tempo passado e as suas experiências, nos traga uma racionalidade que a pressão do presente muitas vezes não nos deixa alcançar. De entre as quatro paredes de uma sala de aula, professores e alunos viram-se obrigados a confinar, durante a pandemia - COVID-19, diligenciando condições para usufruir de um ensino à distância, tornando-se o espaço de suas casas o ambiente virtual da escola. O ensino primário foi o que mais embate sofreu, por estar arreigado a metodologias convencionais e agora sente-se obrigado a "acompanhar" todo este contexto, que veio determinar re(i)novações em catadupa. Apresentamos uma resenha histórica das tendências pedagógicas e das reformas do ensino primário em Portugal.

Palavras-chave: Ensino primário. Zona rural. Tecnologia digital. Resenha histórica. Pandemia-COVID19.

\begin{abstract}
In Education, as in many other areas, we need the past time and its experiences to bring us a rationality that the pressure of the present often does not allow us to reach. Between the four walls of a classroom, teachers and students were forced to confine, during the pandemic - COVID-19, endeavouring conditions to enjoy distance learning, making the space of their homes the virtual environment from school. Primary education was the one that suffered the most, due to being more attached to conventional methodologies and now feels obliged to "follow" this whole context, which came to determine re(i)novations in waterfall. We present a historical overview of pedagogical trends and reforms in primary education in Portugal.
\end{abstract}

Keywords: Primary education. Rural area. Digital technology. Historical review. COVID-19 Pandemic.

Cite como

(ABNT NBR 6023:2018)

NOBRE, Ana; CRUZ, Ema. Educação do século XXI: a resiliência dos professores e as re(i)novações no ensino primário em Portugal. Dialogia, São Paulo, n. 37, p. 1-15, e19736, jan./abr. 2021. Disponível em: https:/ / doi.org/10.5585/dialogia.n37.19736.

American Psychological Association (APA)

Nobre, A., \& Cruz, E. (2021, jan./abr.). Educação do século XXI: a resiliência dos professores e as re(i)novações no ensino primário em Portugal. Dialogia, São Paulo, 37, p. 1-15, e19736. https://doi.org/10.5585/dialogia.n37.19665. 
NOBRE, Ana; CRUZ, Ema. Educação do século XXI: a resiliência dos professores e as re(i)novações no ensino primário em Portugal

Introdução

A situação excecional criada pela pandemia Covid-19, que eclodiu na primavera de $2020 \mathrm{e}$ continua a afetar, em graus variáveis, uma grande parte do mundo, tem restringido fortemente as possibilidades de contato e trocas diretas entre as pessoas. No campo da educação, esforços consideráveis têm sido feitos por todos os atores, sejam eles alunos, pais, professores e lideranças escolares para dar continuidade pedagógica, manter uma forma de contato e garantir o prosseguimento da relação educativa (Mouraz \& Nobre, 2021), pois sabemos que uma interrupção total da relação educativa teria consequências difíceis de reverter na aprendizagem, em particular para os alunos mais vulneráveis.

A educação à distância (E@D) em situação de crise teria sido impossível sem o desenvolvimento dos meios digitais de comunicação que irrigam a nossa sociedade, bem como os intentos dos professores, pais e instituições de ensino para equipar alunos e escolas de tecnologia digital.

Apresentamos brevemente a evolução do ensino primário (dos 6 aos 10 anos), descrevemos as práticas pedagógicas e as lições que podemos extrair de tempos incertos.

Breve resenha histórica do ensino primário em Portugal

O ensino primário tal como o nome indica é "o primeiro", “o pioneiro", “o básico” dos níveis de ensino formais, que se desenvolveu numa peculiaridade de regime de monodocência. Sempre sob a influência de fortes ideologias socioculturais, económicas e políticas, este ensino foi sofrendo transformações, ora evolutivas, ora de retrocesso.

$\mathrm{Na}$ Idade Média, caracterizava-se por um ensino muito elementar - aprendia-se a ler e a escrever, aritmética e adquiriam-se conhecimentos sobre a bíblia, abrangendo, mais tarde, aulas de canto, latim, gramática, retórica e dialética.

No reinado de D. Dinis (1290) é preconizada a organização oficial do ensino público com o aparecimento dos primeiros vestígios do ensino primário (Alves dos Santos, 1977).

O Marquês de Pombal, Ministro do rei D. José I, para além de ter implementado medidas que caracterizaram a reforma geral do ensino, com a Carta de Lei de 1772, como a modernização dos estudos na Universidade de Coimbra à semelhança das universidades europeias e fazendo evoluir o ensino científico, também procede à abertura de Escolas Menores no país e nas colónias portuguesas, onde lecionam professores e "mestres de ler", com o intuito de (re)organizar um ensino primário oficial (Carvalho, 2001). 
Com a Revolução Liberal de 1820, Portugal ganha emancipação política e social. As primeiras Cortes da nacionalidade portuguesa reuniram-se em Lisboa e promulgam a Constituição de 1821, que tem em conta a preocupação com o ensino, por meio da decretação da "liberdade e da generalidade do ensino primário”. No entanto, posteriormente o decreto de 18 de dezembro de 1823 de contra-revolução contrariava a liberdade de ensino contra os bons costumes e princípios dos Governos, levando ao encerramento de todas as escolas "livres" e muitas das escolas oficiais (Alves dos Santos, 1977, cap. III).

No século XIX houve um incremento da atividade escolar, impregnado pelas ideias do liberalismo e influências do despotismo iluminado de Pombal. Foram muitas as leis publicadas e muitas as que não foram concretizadas, por interesses políticos ou por falta de recursos financeiros.

O Decreto de 24 de Dezembro de 1901 organizou o ensino primário em quatro classes, sendo as três primeiras de assiduidade obrigatória e gratuita (1. ${ }^{\circ}$ grau) e a última (2. grau) de frequência opcional ou para quem quisesse prosseguir o ensino secundário-liceal. E sob a autoridade da Direção Geral de Instrução Pública, reinstitui-se o ensino das escolas oficiais e particulares (Coelho, 1976).

Após a implantação da República, dão-se grandes reformas nos vários graus de ensino, nomeadamente a reforma do ensino primário, datada de 1911, que vai abranger o ensino infantil e o ensino normal primário e todas as instituições universitárias voltam a ter a sua autonomia e os recursos necessários ao seu desenvolvimento.

Com o regime do Estado Novo, em 1926, surge a "escola nacionalista" e a educação é reduzida ao ensino primário masculino, ministrado por regentes escolares e o alfabetismo deixa de constituir primazia para o Estado.

A partir da década de 50 do século XX, renasce a preocupação com a alfabetização, pelo que o movimento da Mocidade Portuguesa é alargado ao sexo feminino, com o objetivo de estimular nos jovens "a formação do carácter, a cultura do espírito e a devoção ao serviço social, no amor de Deus, da Pátria e da Família” (Henriques \& Cruz, 2013, p.174) - com influência continuada no governo salazarista, dando primazia à educação postada no ensino primário.

Com a publicação da Lei de Bases do Sistema Educativo, em 1986, o ensino básico é universal, gratuito e constitui obrigatoriedade de frequência dos três ciclos sequenciais (do primeiro até ao nono ano), sendo que o primeiro ciclo vem designar o ensino primário.

O ensino primário tornou-se o principal polo de alfabetização, tendo difundido os mais diversos métodos de leitura e escrita através de pedagogos que se identificavam com a corrente da Escola Nova, anti conservadora, e protagonizou as chamadas Escolas Democráticas com 
NOBRE, Ana; CRUZ, Ema. Educação do século XXI: a resiliência dos professores e as re(i)novações no ensino primário em Portugal

metodologias que possuíam instrumentos, técnicas e práticas construtivas e motivadoras da criatividade e construção do conhecimento e pensamento na criança e adultos (Formosinho, 1998). Como exemplos mais destacados temos a Cartilha Maternal do método de João de Deus (1878), Método Natural de Freinet (1922), Método Paulo Freire de Alfabetização (1963), Jean Qui Rit (2011) que usa os gestos e ritmo, Método das 28 Palavras (2007), o Método Interativo do MEM (1998).

Estas metodologias proporcionaram uma dinâmica própria na organização do trabalho em sala de aula para e com os alunos, dando tempo e espaço à descoberta do conhecimento, promovendo a autonomia na aprendizagem e a apropriação de recursos tecnológicos, desde a mais tenra idade, tendo em consideração o desenvolvimento do espírito crítico, criativo e empreendedor de crianças e jovens, nomeadamente através de jogos e aplicativos digitais.

O Movimento da Escola Moderna (MEM) em Portugal, nasceu da resistência à ditadura de Salazar, em escolas privadas e especiais, de feição iluminista e humanista, assomando um património cultural alargado a todos os níveis de ensino e baseado numa pedagogia sociocêntrica e isomórfica (Niza, 2012). Um movimento pedagógico inovador, criado na década de 60 , que ainda hoje continua a resistir e a lutar pela escola, no sentido de empreender o sucesso de todos os alunos e respeito pela individualidade e capacidades de cada um.

O ensino primário, com nova designação de primeiro ciclo com a Lei de Bases do Sistema Educativo de 1986, adquire uma liberdade no uso de metodologias pelo professor, podendo-se afirmar que predominam duas influências - a tradicional e a moderna. No ensino tradicional, o professor é o principal detentor e o transmissor dos conhecimentos com base no ensino a partir de um livro único e o aluno recebe todo o conhecimento sem contestar ou opinar. A transmissão do conhecimento é unilateral, tendo em conta que os alunos aprendem da mesma forma e ao mesmo ritmo. Na vertente de uma educação moderna, são utilizadas metodologias ativas, em que o aluno torna-se consciente do que é apre(e)ndido, pois integrou o processo de construção, desmaterialização, renovação e atualização do próprio conhecimento (Carneiro, 2003). A aquisição do conhecimento faz-se de forma dinâmica e empreendedora, utilizando o mesmo na intervenção cidadã consciencializada e contribuindo para o bem-estar da comunidade ou sociedade em que se vive. 
NOBRE, Ana; CRUZ, Ema. Educação do século XXI: a resiliência dos professores e as re(i)novações no ensino primário em Portugal

\section{Ensino Primário no século XXI}

Desde os finais do século XX, os professores, para além dos livros em suporte de papel, passaram a usufruir de meios tecnológicos nas escolas como o caso do computador e impressora, construindo materiais digitais e permitindo que os alunos pesquisassem assuntos na Internet, promovendo-se o trabalho em projetos (CARVALHO, 1996).

As funções docentes passaram a ser baseadas na responsabilidade e espírito de colaboração com os pares, alunos e família. As grandes preocupações centram-se no sentido de os alunos desenvolverem valores de cidadania e competências sociais e digitais, através de códigos de conduta que são dados a conhecer pelo professor no seu quotidiano, bem como no uso de ferramentas e plataformas online com segurança, numa perspetiva de alargar os horizontes e abrir janelas para a construção do conhecimento e desenvolvendo o espírito crítico do discente perante o seu olhar e atitudes na sociedade em redor e no mundo atual em que vive (NOBRE, 2018).

As práticas pedagógicas têm em atenção a implementação da legislação - Decreto-Lei n. ${ }^{\circ}$ 54/2018 de 6 de julho na nova redação da Lei n. ${ }^{\circ}$ 116/2019 de 13 de setembro (educação inclusiva)

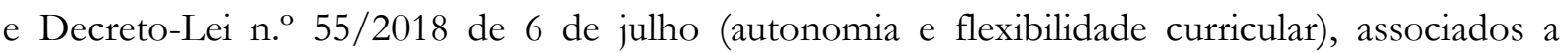
documentos como o Perfil dos Alunos à Saída da Escolaridade Obrigatória, as Aprendizagens Essenciais, o documento da Estratégia Nacional da Educação para a Cidadania e as Orientações Curriculares para as Tecnologias da Informação e Comunicação no $1 .^{\circ}$ Ciclo. Tem-se como referenciais fundamentais as metas e objetivos traçados no projeto educativo do agrupamento. $\mathrm{O}$ professor frui de uma atitude epistemológica, com posição crítica e de atualização permanente face ao conhecimento científico-humanístico, pedagógico/didático, incluindo a transmissão desse saber aos alunos e colegas professores, com quem partilha saberes, debate e esclarece dúvidas, numa perspetiva pedagógica empática e promotora do respeito e da diferença pelas culturas individuais e sociais. A frequência em ações de formação também contribuem para o desenvolvimento pessoal, social e profissional de cada docente. (CONCEIÇÃO; SOUSA, 2012).

A planificação programática, elaborada em grupos de trabalho do Conselho ou Departamento de Docentes, considera os interesses e as necessidades dos alunos, os recursos existentes e uma avaliação contínua e formativa, para que todos os alunos alcancem o sucesso, tendo em conta os documentos homologados em Conselho Pedagógico (Projeto Educativo do Agrupamento, Plano de Atividades Anual e Plano de Turma) e de acordo com as orientações do referido departamento. Existem as reuniões de trabalho colaborativo com a finalidade de planificar os conteúdos e atividades, definir critérios de avaliação, elaborar instrumentos de avaliação e outros materiais pedagógicos, desenvolver projetos. A implementação de medidas dos alunos abrangidos 
pelo Decreto-Lei n. ${ }^{\circ}$ 54/2018 de 6 de julho, em colaboração com a Equipa Multidisciplinar de Apoio à Educação Inclusiva (EMAEI), também está contemplada.

Em cada escola, o grupo de professores reúne sistematicamente para partilha de ideias acerca das práticas implementadas com (re)ajuste de planificações e recursos usados, monitorização de projetos que estão a ser desenvolvidos a nível da escola relacionando com os Domínios de Autonomia Curricular (DAC) ou com professores estrangeiros (e'Twinning - Ação do Programa Erasmus + da União Europeia), verificação e uso de novas ferramentas e plataformas por professores e alunos (Comissão Europeia, 2008).

No ambiente presencial, os alunos tiveram oportunidade de explorar os diferentes espaços da escola (sala de aula, biblioteca, sala de expressões), desfrutarem de saídas ao meio e contactarem com um ambiente virtual pela utilização de ferramentas (Plickers, Padlet) e plataformas (e'Twinning, ClassDojo) digitais, que se caracterizam por aplicativos para aulas online, a fim de pesquisarem e desenvolverem projetos que se referiram sobretudo ao documento DAC, cujos temas se podem relacionar com a disciplina de estudo do meio interligando-se com as outras disciplinas do currículo ou transversais (NOBRE, 2019). A dinamização das atividades procede-se no coletivo, em grupos ou a pares, dando a conhecer sistematicamente o programa aos alunos e levando a cabo estratégias e atividades que desenvolvam competências na compreensão leitora, escrita de textos variados, aplicação das regras gramaticais, ciência experimental, raciocínio lógico-matemático, cálculo mental, resolução de operações e problemas, com recurso a material estruturado e não estruturado, jogos, aulas virtuais, apresentações em PowerPoint, cartazes, vídeos de introdução/exemplificação/consolidação de conteúdos, fichas de trabalho, cadeia de tarefas, grelhas de observação e de avaliação, por forma regular todo o processo de aprendizagem. Os alunos participam nas atividades previstas no Plano Anual de Atividades, em projetos de escola/agrupamento e nas iniciativas da biblioteca escolar e da autarquia, relativas ao $1 .^{\circ} \mathrm{CEB}$, as quais são avaliadas em conjunto com os alunos, durante o ano letivo, como a festa de Natal e Desfile de Carnaval. Mobilizam-se os vários domínios, nomeadamente nas disciplinas de Português e Matemática, articulando conteúdos de outras disciplinas como Estudo do Meio, Artes Visuais e Música. As tarefas realizadas pelos alunos com medidas universais, tiveram em consideração a aplicação do Decreto-Lei no 54/2018 de 6 de julho com as alterações introduzidas pela Lei n. ${ }^{\circ}$ 116/2019 de 13 de setembro. As sequências didáticas permitem a integração curricular em diferentes disciplinas (Português, Matemática, Estudo do Meio e Expressões Artísticas). Também são usadas plataformas e meios tecnológicos como o quadro interativo, Khan Academy, Youtube. 
Os alunos participam em grupo, a pares, individualmente e no coletivo, e com motivação na realização das tarefas propostas.

O incentivo à participação e/ou colaboração dos pais/encarregados de educação nas atividades do Plano Anual de Atividades (PAA) da escola e agrupamento, nos projetos implementados (DAC- Domínios de Autonomia Curricular, e'Twinning) e nas comemorações festivas é uma constante e de extrema importância, no sentido de se proporcionarem momentos de convívio e experiências enriquecedoras, bem como um acompanhamento do educando no seu percurso escolar, divulgando-se as suas realizações e trabalho quotidiano.

A avaliação faz parte de todo o processo ensino-aprendizagem, englobando não só o desempenho do aluno, mas também a reflexão acerca da ação do professor no decorrer das atividades propostas dentro do contexto educativo. Regularmente, são avaliados os objetivos atingidos e as competências desenvolvidas pelos alunos e em conjunto com eles, num regime de auto, co e heteroavaliação. Todo o processo de trabalho diário do aluno e a sua evolução, através de listas de verificação, portefólios, formulários, jogos e questões-aula realizadas de forma oral ou por escrito, assim como os testes escritos, são instrumentos tidos em conta na avaliação dos alunos, em conformidade com os Critérios Gerais e Específicos.

A interação com os alunos e famílias é feita de forma regular e na escola. Convívios, eventos e comemorações são programados de maneira a que a família de cada aluno possa participar de forma pessoal e presencial nas atividades escolares do seu educando.

\section{Ensino à distância}

Num tempo de uma pandemia denominada de COVID 19, as escolas debatem-se com uma mudança no seu ambiente, que requer uma capacidade de reajuste que implica toda a sua estrutura conservadora.

Para além de casos bastante excecionais, o sistema escolar português sempre se baseou, até à primavera de 2020, num ensino "presencial”, associando numa unidade de lugar e tempo alunos e professores. A estratégia nacional de confinamento generalizado, lançada na terça-feira, a 17 de março de 2020, constitui um evento que introduz uma rutura brutal e profunda no sistema educacional.

Na maioria dos países, Portugal inclusive, o fecho de escolas foi acompanhado por uma transição para a educação à distância que trouxe uma grande reviravolta na Educação. Para garantir a continuidade educacional, as escolas optaram por plataformas online, adaptaram tecnologias 
NOBRE, Ana; CRUZ, Ema. Educação do século XXI: a resiliência dos professores e as re(i)novações no ensino primário em Portugal

educacionais que assumiram diversos formatos e realizaram a transição das aulas presenciais para a educação à distância, usando sites e aplicativos para reunir virtualmente alunos e professores.

Em todos os contextos, essa transferência exigiu experimentação, forte apoio de redes préexistentes nas comunidades e adaptação aos contextos individuais das comunidades e dos alunos (NOBRE et al, 2021). Nesta conjuntura extraordinária, o constrangimento de uma E@D “de crise” criou dificuldades que a E@D “clássica” não conseguiu antecipar ou ultrapassar (NOBRE, 2021). Na primavera de 2020, o distanciamento físico e a desagregação da turma decorrente das pressões do confinamento foram imediatos e mecanicamente traduzidos, na escola, por um duplo distanciamento, tanto educacional como social, este último ligado ao rápido abandono escolar e significativo para alguns dos alunos, em particular os mais frágeis.

O distanciamento educacional e, de forma mais geral, toda a crise E@D foram imediatamente submetidos a um verdadeiro "aparato" digital, sem perspetiva crítica suficiente sobre as abordagens didático-pedagógicas em causa (NOBRE; MOURAZ, 2020). E, seja pelo rápido colapso de muitos sistemas de computador, seja pela necessidade de atingir um público pouco ou mal equipado, esse imperativo digital foi associado à obrigação dos professores recorrerem a recursos mais tradicionais (fotocópias, envio de documentos pelos correios, etc.).

Contudo, as consequências do fecho de escolas tiveram e têm um impacto maior nos alunos mais vulneráveis e marginalizados, especialmente no interior de Portugal onde existe falhas significativas nos sistemas educacionais. Os alunos nessas configurações têm menos opções de educação em casa, raramente tendo acesso a computadores, uma conexão de Internet estável, os meios para pagar tudo isso e outros recursos necessários. O encerramento de escolas e as tensões financeiras adicionais, causadas pela desaceleração económica associada ao COVID-19, tornam o risco de absentismo escolar especialmente alto nesta zona do país. Esta situação exigirá maior vigilância e maior supervisão por parte do Estado, mas também esforços significativos por parte da comunidade local.

Ensino primário durante a pandemia (primeiro confinamento em 2020 e segundo confinamento em 2021)

A partir de 16 de março de 2020, as escolas fecham e inicia-se o primeiro confinamento geral em Portugal, abrangendo todos os setores da vida ativa e introduzindo-se o regime de teletrabalho, nomeadamente em empresas e nas escolas (MOREIRA at al. 2020a).

$\mathrm{O}$ ambiente de aprendizagem desenvolveu-se em contexto online, em virtude desse confinamento originado pela pandemia COVID-19. 
No decorrer do confinamento, as planificações foram realizadas em grupos de trabalho, por ano de escolaridade, via online. Algumas estratégias foram reorientadas, bem como os meios tecnológicos a utilizar - foi introduzido o Google Reuniões para as aulas síncronas, o Google Formulários e a ClassDojo como forma de divulgação e monitorização dos trabalhos realizados. Os alunos e encarregados de educação passaram a ter acesso gratuito aos recursos didáticos (vídeos, manuais escolares online), através da Escola Virtual e de outras plataformas educativas, que até aqui eram pagas e adquiridas pelos professores.

O agrupamento de escolas organizou grupos de professores responsáveis na criação do ambiente de ensino à distância, cooperando com o grupo de pares em todo o trabalho desenvolvido de forma colaborativa: introdução à plataforma ClassDojo (criação de contas do professor, aluno e EE, organização das turmas, exploração de funcionalidades tais como fazer "posts" no Diário de Turma, atribuir tarefas aos alunos, contactos com Encarregados de Educação via mensagem, portefólios dos alunos); partilha de dúvidas e questões relativamente às plataformas adotadas, com a identificação de constrangimentos na utilização de meios tecnológicos; esclarecimentos acerca do Google Reuniões - ativação das aulas síncronas através da ClassDojo; identificação de dificuldades na utilização de meios tecnológicos e demonstração de funcionalidades no Google Reuniões (Apresentações, Meet Atendance), Google Forms e Escola Virtual - tendo-se criado e/ou coadjuvado na elaboração de tutoriais a serem usados pelos professores ou encarregados de educação/alunos, como o caso do registo e acesso às plataformas educativas; planificação das atividades da semana pelo grupo/pesquisa, elaboração e partilha de recursos educativos para E@D (MOREIRA at al. 2020b).

A “emissão televisiva de conteúdos pedagógicos” pelo \#EstudoEmCasa (nova "Telescola", um ensino à distância que proliferou em Portugal, entre 1965 e 1987) veio "complementar" o trabalho dos docentes no ensino à distância com os seus alunos, em todos os anos de escolaridade (Sobral, 2020). As emissões do \#EstudoEmCasa iniciaram a 20 de abril de 2020, através da televisão portuguesa, RTP Memória (posição 7).

Neste ano 2021, retomou-se mais um período de ensino remoto de emergência, a 8 de fevereiro, surgindo uma multiplicidade de notícias e opiniões, incluindo novas diretrizes de como deve ser ou não o ensino à distância, salientando-se o documento "Contributos para a implementação do ensino a distância nas escolas", de 2 de fevereiro de 2021, da Direção Geral de Educação (DGE).

As lideranças escolares, tendo em conta a experiência vivenciada no confinamento de 2020 , foram preparando-se de forma mais cautelosa e assertiva para uma nova transição ao ensino à 
distância e em conformidade com as diretrizes emanadas do Ministério de Educação, tendo por base o Decreto n. ${ }^{o}$ 3-D/2021 de 29 de janeiro e Resolução do Conselho de Ministros n. ${ }^{\circ} 53$ D/2020, de 20 de julho. O presente decreto circunscreve a manutenção da vigência das regras constantes no Decreto n. 3-A/2021, de 14 de janeiro, mantendo "a rede de escolas de acolhimento dos filhos ou outros dependentes de trabalhadores de serviços essenciais, bem como apoios a alunos, nomeadamente apoios terapêuticos e medidas adicionais aos alunos com essas necessidades educativas e refeições para alunos beneficiários de ação social escolar". A partir do dia 8 de fevereiro de 2021, "as atividades educativas e letivas dos estabelecimentos de ensino públicos, particulares e cooperativos e do setor social e solidário, de educação pré-escolar e dos ensinos básico e secundário foram suspensas em regime presencial, sendo retomadas em regime não presencial nos termos do disposto na Resolução do Conselho de Ministros n. . 53-D/2020, de 20 de julho". As direções das escolas promoveram o apoio pela equipa tecnológica sobre a utilização das plataformas digitais, tais como Google Classroom, ClassDojo, Meet e Moodle, na lecionação das aulas por videoconferência, sendo as comunicações com a turma, alunos e encarregados de educação, realizadas via email.

Os horários a vigorar durante o Ensino à Distância foram reajustados, em conformidade com a carga horária definida pelos diferentes departamentos e aprovados em Conselho Pedagógico, de forma a haver a máxima equidade na aprendizagem, através da melhor organização das atividades letivas e não letivas, tomando em consideração:

- a distribuição de tempos síncronos e assíncronos, despendendo o tempo necessário em ecrã e o tempo de trabalho autónomo, de acordo com a especificidade de cada turma e dos alunos que a integram;

- os alunos a continuar em ensino presencial: alunos com deficiências, alunos provenientes de famílias em risco e sem condições de acompanhamento ao seu educando, alunos de PLNM Português Língua Não Materna, alunos sob a alçada da Comissão de Proteção de Crianças e Jovens, alunos em risco de abandono escolar e alunos em escola de acolhimento (Portaria n. ${ }^{\circ} 25-\mathrm{A} / 2021$, de 29 de janeiro).

Neste período de pandemia, Ensino Remoto de Emergência 2.0, o \#EstudoEmCasa através da parceria do Ministério da Educação (ME) com a RTP e com o apoio das Editoras Leya e Porto Editora, disponibilizou recursos didáticos aos professores, do $1 .^{\circ}$ ao $12 .^{\circ}$ anos de escolaridade. Todas as componentes curriculares dos cursos são transmitidas, conjuntamente com a interpretação em língua gestual portuguesa. 
Todos os conteúdos, do Básico ao Secundário, permanecem disponíveis na RTP Play, através da app \#EstudoEmCasa e nas plataformas de videoclube nas diferentes operadoras.

Entidades, instituições de solidariedade social e autarquias cancelaram eventos e projetos, como a Comemoração do Dia Mundial da Criança e a Feira do Livro. Houve projetos escolares que não puderam ser continuados nem finalizados, pois as atividades tinham sido programadas para o ambiente de ensino presencial.

O contacto da escola e dos docentes com alunos e encarregados de educação começou a ser feito via online (emails, videoconferência), via telefónica (Whatsapp) ou nas redes sociais (Messenger), sendo mais dificultado, na medida em que existem grandes impasses na rede de internet e falta de meios tecnológicos - a maioria dos encarregados disponibilizou aos seus educandos um Smartphone para assistirem às aulas síncronas e tiveram de providenciar o reforço da internet nas suas casas (MOURAZ; NOBRE, 2021). As aulas síncronas têm a duração de três horas a quinze horas semanais no primeiro ciclo, dependendo do horário estipulado em cada agrupamento, preenchendo-se a restante mancha horária dos alunos com tempos assíncronos, que contemplam o apoio direto do professor titular e o professor de apoio educativo. Nas turmas com mais de um ano de escolaridade e o máximo de quatro (alunos do $1 .^{\circ}, 2 .^{\circ}, 3 .^{\circ}$ e $4,^{\circ}$ anos) teve-se de disponibilizar mais horas de aulas síncronas, para abranger todos os alunos de forma mais equitativa. Aproveitam-se uns minutos após as aulas síncronas para “atender” os encarregados de educação. Muitos pais/encarregados de educação necessitaram de ajuda por parte do professor, que empregou horas do seu tempo, na instalação dos diversos aplicativos usados nas aulas online (Meet, ClassDojo) em computadores, tablet, smartphone. Tiveram de se ajustar horários, porque muitos encarregados de educação não estavam abrangidos pelo regime de teletrabalho. Os alunos abrangidos pela educação especial e por terapias continuam a não ser devidamente acompanhados, devido a algumas terem sido adiadas, como o caso das terapias com animais.

Pode-se afirmar o facto de se ter notado uma atualização constante nos meios tecnológicos e plataformas, aplicativos ou extensões digitais, que proporcionaram mais funcionalidades (Meet Atendance, que permite o registo de presenças dos alunos nas aulas síncronas), nomeadamente durante o contexto da pandemia.

A relação entre os professores, os alunos e as famílias continuaram o mais próximas possível, considerando as necessidades educativas e terapias dos educandos, as condições de espaço e conforto em suas casas, a carência de meios tecnológicos, entre outros... ainda que à distância. 
NOBRE, Ana; CRUZ, Ema. Educação do século XXI: a resiliência dos professores e as re(i)novações no ensino primário em Portugal

Manter a experiência adquirida durante o primeiro confinamento (2020) e segundo confinamento (2021) e estar pronto para um terceiro!

Ninguém sabe exatamente em que direção a pandemia irá evoluir. Trazer os alunos de volta às escolas e instituições é uma prioridade, mas no momento da redação deste trabalho está claro que as medidas de distanciamento e as precauções de saúde permanecerão em vigor durante, pelo menos, o ano civil de 2021.

Após este segundo confinamento (de janeiro a março de 2021) as situações que se apresentarão aos professores serão diferentes daquelas que encontraram no primeiro "desconfinamento". A maior parte deles já tem experiência na utilização de ferramentas de comunicação digital com alunos (Classroom, ClassDojo, Teams) e podem contar com a sua prática do ensino à distância, que adquiriram durante estes dois confinamentos, na identificação dos recursos úteis que têm transportado e nas estratégias de avaliação e personalização que eles implementaram.

É importante garantir que as competências adquiridas durante a pandemia COVID-19 não se percam e os professores tenham a ousadia de continuar a desenvolver o processo educativo de forma sempre inovadora e criando a sua própria dinâmica em conjunto com os seus alunos.

No que respeita à educação, sabe-se que no ensino presencial se adaptam todas as tecnologias digitais existentes. Professores, alunos e famílias fizeram um enorme esforço para adquirir os meios digitais necessários, sendo que os alunos com ação social obtiveram ajudas do Estado.

Por outro lado, a dificuldade dos professores em lecionarem determinados conteúdos mais práticos (desenhos de letras, geometria, operações com algoritmos - utilizando-se aplicações como o Whiteboard), agravada pelo facto de os alunos do primeiro ciclo não terem autonomia para lidar com os meios digitais utilizados, necessitando permanentemente do acompanhamento dos encarregados de educação. Também é de salientar a mancha horária muito rígida, o que provoca nos professores, alunos e famílias exaustão, por estarem muitas horas em frente ao computador.

Para isso, será necessário que as instituições mantenham o seu foco na formação de professores, para que haja continuidade nas práticas implementadas em ambos os confinamentos e que auxiliem os professores no seu processo autorreflexivo. Também é essencial que, a nível local, as equipas educacionais e disciplinares tenham tempo para analisar em conjunto as lições aprendidas em 2020 e 2021. As ações de formação local podem basear-se nessa experiência e as equipas devem estar prontas para fazer a transição rápida de uma modalidade de ensino existente 
NOBRE, Ana; CRUZ, Ema. Educação do século XXI: a resiliência dos professores e as re(i)novações no ensino primário em Portugal

para uma situação integral de educação à distância. Não sabemos se haverá um terceiro confinamento, mas todos deverão estar alertos e (ainda) melhor preparados para tal eventualidade.

\section{Conclusão}

O ambiente educativo virtual criado pelo contexto da pandemia COVID 19, trouxe vantagens e também dissabores. Até há uma década atrás, os professores raramente usavam o computador que tinham em cima da sua secretária - liam apenas alguns emails, elaboravam relatórios e faziam os testes para os alunos. Com a implementação de plataformas como o Moodle e o GIAE (portal onde constam os processos individuais dos alunos pertencentes a um agrupamento de escolas), foram usando cada vez mais o computador, por imposição dos agrupamentos onde lecionavam, registando as faltas e as avaliações dos alunos nas respetivas plataformas. Havia os professores que implementavam aulas virtuais com os seus alunos, inicialmente recorrendo a cassetes de audio ou CD e, mais tarde, ao Google Pesquisa e ao Youtube, que continham também recursos muito limitados.

Hoje em dia, existe uma panóplia de sites, com uma atualização significativa em plataformas, como a Wikipédia e a pesquisa no Google. Os motores de pesquisa diversificaram a oferta, nomeadamente no que respeita à educação.

É certo que se criaram as condições mínimas e as ferramentas necessárias para trabalhar e as interrelações entre professores, alunos e famílias aumentaram. O esforço em conseguir a presença de todos os alunos, de orientar e adequar a lecionação de conteúdos e a sua avaliação à modalidade de ensino à distância, promovendo aulas dinâmicas e fomentando a autonomia dos alunos na realização das tarefas, o conhecimento diversificado de ferramentas digitais, exigiram do professor uma enorme capacidade de adaptação e uso de empatia para cativar não só os alunos mas também as famílias, mantendo um feedback regular e regulador.

As falhas de internet ou energia ou nos equipamentos técnicos, nenhum profissional as pode controlar, assim como a solidão e o cansaço ou até mesmo a impotência para resolver problemas de desigualdade dos alunos na iliteracia digital, na privacidade e espaço de estudo nas suas casas, o conseguir resolver as necessidades com que se deparam, no captar a sua atenção e motivação para as aprendizagens.

O futuro é incerto, mas pode-se afirmar convictamente que, a cada dia que passa, os professores tentam fazer o melhor que se pode, ultrapassar desafios contantes, atender às necessidades de todos e, sobretudo, arranjar soluções para os problemas que surgem no dia-a-dia.

O que se passa por detrás do ecrã, fica por ora na "escola" de cada um. 


\section{Dialogia}

NOBRE, Ana; CRUZ, Ema. Educação do século XXI: a resiliência dos professores e as re(i)novações no ensino primário em Portugal

\section{Referências}

ALVES dos SANTOS, A. J. O Ensino Primário em Portugal. Revista Escola Democrática. Lisboa, Direção-Geral do Ensino Básico. Maio-Junho de 1977.

CARNEIRO, A. H. Evolução e controlo do ensino em Portugal: da fundação da nacionalidade ao 1. ${ }^{\circ}$ Ministério da Instrução pública. Lisboa: Fundação Calouste Gulbenkian, 2003

CARNEIRO, Roberto ( $2^{a}$ ed.). Fundamentos da educação e da aprendizagem: 21 Ensaios para o século 21. Vila Nova de Gaia, Fundação Manuel Leão. 2003.

CARVALHO, R. História do Ensino em Portugal - Desde a Fundação da Nacionalidade até ao fim do regime de Salazar-Caetano . Fundação Calouste Gulbenkian. Lisboa. 1996.

COELHO, F. Portugal (História da Instrução). Revista Escola Democrática. Lisboa, Direção-Geral do Ensino Básico. Março de 1976.

COMISSÃO EUROPEIA. Melhorar as competências para o século XXI: Uma agenda para a cooperação europeia em matéria escolar. Bruxelas. 2008

CONCEIÇÃO, C., SOUSA, O. Ser professor hoje. O que pensam os professores das suas competências. Revista Lusófona de Educação, 20. 2012.

FORMOSINHO, J. O Ensino Primário: De ciclo único do ensino básico a ciclo intermédio da educação básica. Lisboa: Ministério da Educação.1998.

HENRIQUES, B., CRUZ, E. Pedrógão Pequeno. Joia do Cabril. Pedrógão Pequeno: Junta de Freguesia de Pedrógão Pequeno. 2013.

NIZA, S. Escritos sobre Educação. Lisboa: Tinta-da-China. 2012

NOBRE, A. Explorando Desafios Pedagógicos Digitais no Ensino Profissional durante a Pandemia - Covid-19. In Em Rede, Revista de Educação a Distância. 2021. Aguarda publicação

NOBRE, A. The Pedagogy That Makes the Students Act Collaboratively and Open Educational Practices. In Personalization and Collaboration in Adaptive e-learning. IGI Global. 2019.

NOBRE, A. Digital: Multidisciplinary and multidimensional in the classrooms. In Global e-learning (pp. 77-98). Academic Press. 2018.

NOBRE, A., MOURAZ, A. Reflexões sobre os efeitos da pandemia na aprendizagem digital. In O (Re)inventar da Educação em Tempos de Pandemia. Dialogia. São Paulo, n. 36, p. 367-381, set./dez. 2020.

NOBRE, A., MOURAZ, A., GOULÃO, M. F., HENRIQUES, S., BARROS, D., MOREIRA, J. A., Processos de Comunicação Digital no Sistema Educativo Português em Tempos de Pandemia. In Educação e Cultura Digital na COVID-19, Revista PRÁXIS Educacional. v.17, n.45, p. 1-19, abr./jun. 2021 


\section{Dialogia}

NOBRE, Ana; CRUZ, Ema. Educação do século XXI: a resiliência dos professores e as re(i)novações no ensino primário em Portugal

MOREIRA, J. A., HENRIQUES, S., BARROS, D.. Transitando de um ensino remoto emergencial para uma educação digital em rede, em tempos de pandemia. Dialogia. 34, 351-364. (2020a). https://doi.org/10.5585/Dialogia.N34.17123

MOREIRA, J. A., HENRIQUES, S., BARROS, D., GOULÃO, M. F., CAEIRO, D. Educação Digital em Rede: princípios para o design pedagógico em tempos de pandemia. Universidade Aberta. (2020b). https://doi.org/10.34627/rfg-0-ps07

MOURAZ. A., NOBRE, A. Change life to Online: Pedagogical Relationship in Pandemic Time, EDEN 2021 Annual Conference. 2021

SOBRAL, S.R. O impacto do covid-19 na educação. 2020. Retirado de: https://observador.pt/opiniao/o-impacto-do-covid-19-na-educacao/ 